\title{
A patient with periorbital pain: A case of isolated schwannoma of the eyebrow
}

\author{
Aslı Duran ${ }^{1}$, Alpay Duran ${ }^{2 *}$, Hasan Dindar ${ }^{3}$, Tuğba Dindar ${ }^{2}$ \\ ${ }^{1}$ Department of Dermatology, Sanliurfa Balikligol State Hospital, Sanliurfa, Turkey \\ ${ }^{2}$ Department of Plastic, Reconstructive and Aesthetic Surgery, Sanliurfa Mehmet Akif Inan Training and Research Hospital, Sanliurfa, Turkey \\ ${ }^{3}$ Department of Pathology, Sanliurfa Mehmet Akif Inan Training and Research Hospital, Sanliurfa, Turkey
}

\begin{abstract}
Schwannomas rarely occur around the orbit and they commonly arise in patients between ages 20 and 70 as unilateral masses with well-defined borders and with a rather slow growth rate. There are only a few case reports with lower and upper eyelid involvement in the English-language literature. In this report, an isolated schwannoma case with eyebrow involvement on the trajectory of the supraorbital nerve in a 24 -year-old male patient is presented.

Keywords: Schwannoma; eyebrow; supraorbital nerve

Citation: Duran A, Duran A, Dindar H, Dindar T. A patient with periorbital pain: A case of isolated schwannoma of the eyebrow. J Surg Dermatol 2017; 2(1): 43-45; http://dx.doi.org/10.18282/jsd. v2.i1.104.
\end{abstract}

*Correspondence to: Alpay Duran, Department of Plastic, Reconstructive and Aesthetic Surgery, Sanliurfa Mehmet Akif Inan Training and Research Hospital, Sanliurfa, Turkey, dr.alpayduran@ hotmail.com.

Received: $29^{\text {th }}$ October 2016; Accepted: $9^{\text {th }}$ November 2016; Published Online: $4^{\text {th }}$ January 2017

\section{Introduction}

Schwannomas, first described by Uruguayan neuropathologist Jose Verocay in 1908, are benign tumors arising from the neuroectodermal cranial, intraspinal, peripheral or autonomous nerve sheaths. Schwannomas rarely occur around the orbit and they commonly arise in patients between ages 20 and 70 as unilateral masses with well-defined borders and with a rather slow growth rate $^{[1]}$. Although these tumors can develop in any part of the orbit, they most commonly involve the ophthalmic branch of the trigeminal nerve. However, schwannomas can also arise from the 3rd, 4th and 6th cranial nerves as well ${ }^{[2,3]}$. It has been reported that some hereditary diseases such as neurofibromatosis, schwannomatosis and Carney complex are associated with multiple schwannomas ${ }^{[4]}$. There are only a few case reports with lower and upper eyelid involvement in the English-language literature ${ }^{[4-15]}$. In this report, an isolated schwannoma case with eyebrow involvement on the tra- jectory of the supraorbital nerve in a 24-year-old male patient is presented.

\section{Case report}

A 24-year-old male patient was admitted to our outpatient clinic with complaint of a painful mass at the medial part of the eyebrow. In his medical history, he stated that the mass had grown slowly over the past four years. Physical examination revealed a mobile, hard-nodular lesion measuring $4 \times 2 \mathrm{~cm}$. No café au lait spots, axillary or inguinal freckles, and neurofibromas suggesting neurofibromatosis were observed during the dermatological examination of the patient. Ophthalmological examination revealed a 20/20 visual acuity and normal eye movements in each eye. During fundus and anterior segment examinations, no Lisch nodules - which are among the diagnostic criteria of neurofibromatosis were detected. In computerized tomography and orbital magnetic resonance imaging, a mass located on the anterior of supra-orbital rim was detected. The mass was 
reported to be extraorbital, homogenous, having distinct borders and a capsule, and measuring at $39 \times 21$ $\mathrm{mm}$. It was isodense to muscle tissue. No sphenoid wing dysplasia, pseudarthrosis or thinning of long bone cortex was detected.

Total excision of the mass was performed in a plastic surgery clinic, preserving the supraorbital and supratrochlear nerve, levator palpebre superioris and orbicularis oculi muscle. There was no functional and sensory impairment of the eyelid and eye brow movements (Figure 1). Histopathological examination of the mass reported that it was consistent with schwannoma, containing compact hypercellular Antoni A areas and myxoid hypocellular Antoni B areas. Intense positivity was observed for S-100 protein immunohistochemical staining. It was detected that the cells were narrow, elongated and wavy, and Verocay bodies were observed in cellular areas (Figures 2A and 2B). There was no complication post-operation, and no relapse developed after one-year follow-up of the patient.

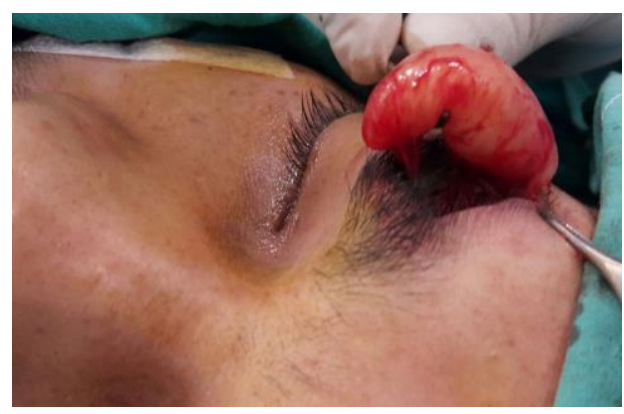

Figure 1. Perioperative view of the case

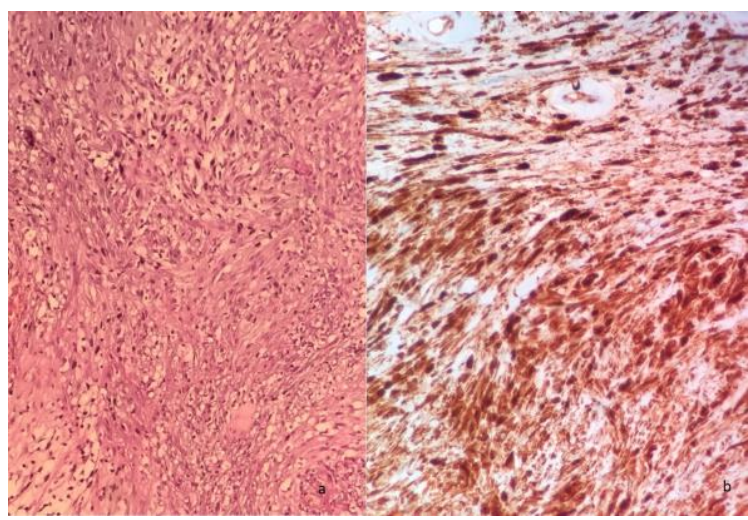

Figure 2. (A) Compact hypercellular Antoni A areas and myxoid hypocellular Antoni B areas. Cells are narrow, elongate, and wavy with tapered ends interspersed with collagen fibers. Nuclear palisading around fibrillary process (Verocay bodies) are often seen in cellular areas (Hematoxylin and eosin (H\&E), 200X); (B) S-100 staining of the lesion.

\section{Discussion}

Ninety percent of the schwannomas are solitary and isolated. Common clinicopathologic variants of schwannomas include conventional, cellular, cystic and melanocytic schwannoma. Schwannomas arise from the proliferation of periaxonal or endoneural Schwann cells. Although a defect or loss in type-2 NF gene located in the chromosome 22 has been implicated for the Schwann cell proliferation, its real cause remains unknown.

Schwannomas have the appearance of solitary, soft, pink-yellow, smooth nodule or tumor localizing in deep dermis or subcutaneous tissue. They are almost always found within a capsule. Their dimensions can range between $0.5 \mathrm{~cm}$ and $3 \mathrm{~cm}$. They most commonly involve the flexor surfaces of the extremities, followed by the wide nerve bodies along the head and neck region. The tumor cells have a cylindrical or spindle-shaped appearance, and they are usually wavy. They consist of hypercellular (Antoni A) and hypocellular (Antoni B) areas. Hard schwannomas appear tightly organized in under macroscopic examination and contain intense Antoni A areas. Their nuclei comprise palisades of basophilic Schwann cells divided by bright eosinophilic areas (Vecoray bodies). Soft schwannomas are edematous; they are composed mostly or completely of Antoni B tissue characterized by loose connective tissue and ectatic blood vessels. Schwannoma is stained positive for S-100 and negative for epidermal membrane antigen (EMA) in immunohistochemical examination.

Differential diagnosis of schwannoma includes lipoma, fibroma, xanthoma, hemangioma, hemangiopericytoma, leiomyoma, fibrosarcoma, leiomyosarcoma, solitary fibrous tumor, adnexal tumors and meningiomas ${ }^{[16]}$. Differentiation from these tumors can be challenging because schwannomas are also painless, mobile and soft. When cystic degeneration is present, schwannomas can be confused with mucocele, dermoid cyst, pyocele, meningoencephalocele, hematocele, epidermal inclusion cyst, ganglion cyst and teratoma ${ }^{[3]}$.

Detection of the origin of the tumor can be difficult due to its complex orbital anatomy. Nerve origin can be found in only $32 \%$ to $47 \%$ of orbital schwannomas. The tumor is mobile on the horizontal plane of the nerve line, while it is frequently fixated on a vertical plane. Although it is commonly manifested by painless proptosis, it can cause complaints of numbness or findings imitating sinusitis, as in our case ${ }^{[17]}$. When found around the eye globe, the localization of the tumor becomes important because of the movement of the globe. Di- 
plopia and eccentric proptosis are among the common findings in intraconal lesions. Similar to that of our case, however, extraorbital tumors result in minimal changes in orbital structures because they are slow-growing masses ${ }^{[18]}$. Since most cases with schwannomas exhibit supraorbital and supratrochlear nerve localization, the globe is displaced downwards. The tumor rarely arises from infraorbital nerve, and pushes the globe upwards.

The treatment of extraorbital schwannomas involves total excision of the mass with its capsule. In some cases, adhesion of the mass to adjacent tissues does not permit total resection and tumor relapse can be encountered. Prognosis is good and relapse rate is low in patients who undergo complete surgical excision.

\section{Conclusion}

Schwannomas are uncommon tumors. Preoperative diagnosis can be challenging because of the variability of locations and the absence of pathognomonic characteristics. It is important to perform early diagnosis with CT scan and orbital MRI followed by early intervention in suspected lesions during early stage in order to prevent serious complications.

\section{Acknowledgements}

All authors were involved in drafting the article and all authors approved the final version to be submitted for publication. All authors have contributed significant intellectual value to the manuscript.

\section{Conflict of interest}

The authors declare no potential conflict of interest with respect to the research, authorship, and/or publication of this article.

\section{References}

1. Garg R, Dhawan A, Gupta N, D'souza P. A rare case of benign isolated schwannoma in the inferior orbit. Indian $\mathrm{J}$ Ophthalmol 2008; 56(6): 514-515. doi: 10.4103/03014738.43380

2. Hayashi Y, Watanabe T, Kita D, Hayashi Y, Takahira M, et al. Orbital cystic schwannoma originating from the frontal nerve. Case Rep Ophthalmol Med 2012; 2012: 604574. doi: 10.1155/2012/604574.

3. Lam DSC, Ng JSK, To KF, Abdulah V, Liew CT, et al. Cystic schwannoma of the orbit. Eye 1997; 11(Pt 6): 798-800. doi: 10.1038/eye.1997.208.

4. de Sá Coutinho M, Meyer I, Jungmann P, de Souza Filho
JP. Schwannoma em pálpebra superior esquerda em criança de 10 anos (Portugese) [Schwannoma of the left superior eyelid in a 10-year-old child]. Rev Bras Oftalmol 2014; 73(2): 117-119. doi: 10.5935/0034-7280.20140026.

5. Baijal GC, Garg SK, Kanhere S, Monga S. Schwannoma of the eye-lid. Indian J Ophthalmol 1980; 28(3): 155-156.

6. Shields JA, Guibor P. Neurilemoma of the eyelid resembling a recurrent chalazion. Arch Ophthalmol 1984; 102(11): 1650. doi: 10.1001/archopht.1984.01040031340022 .

7. Shields JA, Kiralti H, Shields CL, Eagle RC Jr, Luo S. Schwannoma of the eyelid in a child. J Pediatr Ophthalmol Strabismus 1994; 31(5): 332-333.

8. Siddiqui MAR, Leslie T, Scott C, MacKenzie J. Eyelid schwannoma in a male adult. Clin Exp Ophthalmol 2005; 33(4): 412-413. doi: 10.1111/j.1442-9071.2005.01035.x.

9. López-Tizón E, Mencía-Gutiérrez E, Gutiérrez-Díaz E, Ricoy JR. Schwannoma of the eyelid: Report of two cases. Dermatol Online J 2007; 13(2): 12.

10. Chung YR, Moon S, Jang JW. Eyelid schwannoma in a Korean Woman. Jpn J Ophthalmol 2007; 51(3): 231-232. doi: 10.1007/s10384-007-0432-7.

11. Touzri RA, Errais K, Zermani R, Benjilani S, Ouertani A. Schwannoma of the eyelid: Apropos of two cases. Indian J Ophthalmol 2009; 57(4): 318-320. doi: 10.4103/03014738.53063

12. Cheng KH, Karres J, Kros J, Kijlstra A, van Dekken H. Cyst-like schwannoma on the eyelid margin. J Craniofac Surg 2012; 23(4): 1215-1216. doi: 10.1097/SCS.0b013e3182564ace.

13. Mandal SK, Mandal A, Biswas BK. Giant upper eyelid schwannoma with total upper lid. J Case Rep 2014; 4(2): 278-282. doi: 10.17659/01.2014.0070.

14. Gelincik I. Right upper eyelid schwannoma in a child: A case report. J Clin Exp Pathol 2012; 2: 116. doi: 10.4172/2161-0681.1000116.

15. Oltulu P, Oltulu R, Turan M, Erşan İ. Schwannoma of the eyelid: A case report. Int J Clin Res 2014; 2(3): 119-122.

16. Schwartz TH, Bruce JN. Extended frontal approach with bilateral orbitofrontoethmoidal osteotomies for removal of a giant extracranial schwannoma in the nasopharynx, sphenoid sinus, and parapharyngeal space. World Neurosurg 2001; 55(5): 270-274. doi: 10.1016/ S0090-3019(01)00419-0.

17. Dervin JE, Beaconsfield M, Wright JE, Moseley IF. CT findings in orbital tumours of nerve sheath origin. Clin Radiol 1989; 40(5): 475-479. doi: 10.1016/S0009-9260 (89)80250-8.

18. Gündüz K, Kurt RA, Erden E. Orbital schwannoma with fluid-fluid levels on MRI. Ophthal Plast Reconstr Surg 2011; 27(3): e51-e54. doi: 10.1097/IOP.0b013e3181e2f$96 f$. 